\title{
ENDOGLIN EXPRESSION AS A MEASURE OF MICROVESSEL DENSITY IN ORAL HEAD AND NECK CANCER BY IMMUNOHISTOCHEMICAL STUDY
}

\author{
Marwa Mohamed Mustafa Maghrabi* and Asmaa Salam Nouri Algharyani*
}

\begin{abstract}
Background and Aim: Tumor growth is limited by the balance between the need for oxygen and nutrients and diffusion of these substances from vessels around tumors. Therefore, angiogenesis, development of new blood vessels from previous blood vessels, is necessary for tumor growth and metastasis. This study was carried out with the aim of evaluating the angiogenesis in oral cancer by assessing microvessel density (MVD) using Endoglin (CD105). This work also correlated the expressions of marker with histopathological grades of oral squamous cell carcinoma.
\end{abstract}

Material and Methods: Immunohistochemical staining with Streptavidin peroxidase was used to analyze the CD105 expression in 25 cases of oral squamous cell carcinoma.

Results: All studied cases showed positive of CD105 immunoreactivity. The study revealed a highly significant increase of CD105-MVD in poorly differentiated OSSC than well differentiated OSCC.

Conclusion: Increased expression of CD 105 in high grade tumors suggests that Endoglin is likely to contribute significantly to resistance in response to therapy.

KEY WORDS: Angiogenesis, Microvessel density (MVD), Endothelial cells (ECs), CD105 and Oral Squamous Cell Carcinoma (OSCC).

\section{INTRODUCTION}

Oral cancer is one of the major worldwide health problem due to high incidence, reduce survival rate and also to functional and cosmetic deficiency that accompany the disease and treatment. Oral squamous cell carcinoma (OSCC) is the sixth commonest cancer in the world. Although improvements have been achieved in surgical techniques, radiation therapy protocols, and chemotherapeutic regimes, the overall 5-year survival rate for this disease remains at 50\% and has not significantly improved in the past 30 years [Parkin et al 2000].

\footnotetext{
* Lecturer Assistant in Oral Pathology Department, Faculty of Dentistry, University of Tripoli / Libya.
} 
The incidence of OSCC has increased in many countries, especially in younger age groups. The oral tongue is the most common site and is associated with higher mortality than OSCC in other sites (e.g. floor of mouth, gingivae, and retromolar trigone) (Farhood et al., 2019).

During the process of its growth, OSCCs invade and metastasize and hence new blood vessel formation is critical as such. Adequate amount of blood supply is created by stimulating endothelial cell proliferation and new angiogenesis to compensate the shortage of blood supply. This angiogenesis is an essential part of solid tumor formation (Farhood et al., 2019).

Tumor cells release growth factors that stimulate proliferation and migration of endothelial cells (ECs) to form a new irregular network of vessels that provides nutrients and oxygen that promote tumor cell proliferation, tumor progression and development of distant metastasis (Weidner, 2000 and Sebti and Hamilton, 2000).

Regulatory mechanisms in angiogenesis are physiologically governed by a homeostatic balance between positive and negative angiogenic regulators, so that neovascularization is normally suppressed (Reinmuth et al., 2003).

Microvessel density (MVD) is an important factor which reflects tumor angiogenesis and is considered as a potential prognostic marker in numerous tumors (Duff et al., 2007).

MVD is a good indicator of therapeutic efficacy, as there is a positive correlation between MVD and tumor recurrence. Also, it is an important marker to determine the prognosis in many human malignancies as the survival rate decreases with increased MVD (Nico et al., 2008).

Angiogenesis is determined by immunohistochemical assessment of several endothelial cell markers in which Endogelin (CD105) is an angiogenic factor expressed in activated endothelial cells and is associated with neovasculature. CD31, CD34 and vascular endothelial growth factor (VEGF) are pan endothelial markers (Basnaker 2014).

\section{Endoglin(CD105):}

CD105 is a 180 kilodalton $(\mathrm{kDa})$ phosphorylated transmembrane glycoprotein, its gene is located on chromosome 9. CD105 is a component of TGF- $\beta$ receptor complex which is mainly expressed on active immature endothelial cells (Ecs). Consistently, higher levels of CD105 expression are detected on human microvascular ECs in tissues undergoing active angiogenesis, such as inflamed and regenerating tissues or tumors (Fonsatti et al., 2000 and Dallas et al., 2008).

Two isoforms of endoglin exist, $\mathrm{L}$ and $\mathrm{S}$, and they differ in the length of the intracellular domain, tissue distribution and degree of phosphorylation. L-Endoglin contains 47 amino acids in the cytoplasmic tail, has a high degree of phosphorylation and is predominantly expressed in endothelial cells, whereas S-endoglin contains only 14 amino acids (Cheifetz et al 1992\& Bellon et al., 1993).

Both isoforms are constitutively phosphorylated and this is likely due to the constitutively active TGF- $\beta$ receptor type II (TGF- $\beta$ R2) (Guerreroet al., 2002). A soluble form of endoglin has also been identified in the sera of healthy and cancer patients. Elevated levels of soluble endoglin have been noted in sera of patients with diseases such as metastatic melanoma, and breast cancer patients at risk of metastasis (Li et al., 2000 \&Fonsatti et al., 2001).

Endothelial cells of blood vessels are the main source of CD105. Other cells including vascular smooth muscle cells, fibroblasts, macrophages, can also express CD105 to a lesser extent (Zijlmans et al., 2009). Expression of this marker can be also observed in non-neoplastic tissue with increased angiogenic activity such as embryonic development and wound healing (Hillen, 2007) 
In various studies the relationship between MVD (by using CD105 marker) and factors such as metastasis, stage of tumor, proliferation rate of tumor cells and survival has been investigated (Liu et al., 2012). In a study made by Tadbir et al (2012), significant increase of blood vessels in malignant salivary gland tumors in comparison with benign salivary tumors has been observed. Another study made by Cordoso et al. 2009) also evidenced that neoplastic development in salivary tumors does not always require prominent angiogenesis.

\section{Aim of The study:}

1- The objective of the study is to investigate the immunohistochemical Expression of CD 105 in oral squamous cell carcinoma (OSCC).

2- In addition, to correlate the expression of CD 105 with histopathological grade of Tumor.

\section{MATERIAL AND METHODS}

Twenty five cases of paraffin blocks were investigated in this study from all the paraffin blocks, tissue sections were cut and stained with hematoxylin and eosin stains, re-diagnosed to confirm the previously made diagnosis, were 15 specimens of well differentiated OSCC and 10 specimens were poorly differentiated carcinoma collected from the archival files of General Pathology Department of Tripoli University Hospital between 2015 and 2019. Serial section $4 \mu \mathrm{m}$ thick were taken from tissue blocks and processed for immunohistochemical examination.

\section{Immunohistochemical staining:}

For immunohistochemical examination, the primary antibody used was rabbit polyclonal antibody raised against a recombinant protein corresponding to Human CD105 which is an affinity purified mouse monoclonal antibody (Clone SN6h) obtained from Thermo Scientific, Runcorn, Cheshire WA7, UK. The dilution of this product in phosphate buffer solution (PBS) was (1:100).
Three serial sections (4 microns thick) were cut from each paraffin block and were placed on the positively charged slides for the staining procedure.

Sections were deparaffinized with xylene and rehydrated in graded alcohol. Endogenous peroxidase activity was blocked by incubating sections with $0.3 \% \mathrm{H} 2 \mathrm{O} 2$ in methanol for 10 minutes. Primary antibody was added. The section were stained with anti-CD 105 antibody. 2-3 drops of biotinylated reagent were placed on each slide to cover the sections completely.

Streptavidin peroxidase solution label were placed on each slide was added similarly and the incubation condition were repeated. Diaminobenzidine stain was applied to detect chromogenesis.

\section{RESULT}

\section{I-Histopathological Findings:}

\section{Oral Squamous Cell Carcinoma;}

1- Well- differentiated carcinoma showed the following features:

The neoplastic epithelium was squamous with obvious formation of keratin pearls or cell nests. The tumor cells showed slight hyperchromatism, slight pleomorphism and few mitotic figures. Inflammatory reaction, mainly surrounded the keratin pearls, could be seen, figure (1).

2-Poorly differentiated carcinoma cases revealed diffuse sheets of malignant epithelial cells invading the underlying connective tissue. Neither keratin pearls nor individual cell keratinization could be detected. There were extreme nuclear and cellular pleomorphism, hyperchromatism and aberrant mitotic figures. Numerous inflammatory cells were interspersed within tumours tissue, figure (2).

\section{II-Immunohistochemical Findings:}

Our results showed CD 105 immunopositivity in $21 / 25(84 . \%)$ of OSCC cases and in (90\%) in poorly 
differentiated OSCC and $73 \%$ in well differentiated OSCC

\section{Oral Squamous Cell Carcinoma:}

Twelve out of 15 studied cases $(73 \%)$ of well differentiated oral squamous cell carcinoma revealed weak to moderate CD 105 immunopositivity. Whereas, $8(66.6 \%)$ cases showed weak immunoreactions, 4(33.3\%) cases showed moderate immunostain.

Nine out of 10 studied cases (90\%) of poorly differentiated oral squamous cell carcinoma were CD105 positive. 2 (22.2\%) cases showed moderate immunoreactivity and $7(77.7 \%)$ cases showed strong immunoreactivity.

\section{III-Statistical Analysis:}

By using Student's t-Test:

High significant difference in the mean values of the total score of CD105 immunoexpression was detected between well and poorly differentiated OSCC, Table (2), and graph (1).

There is a statistically significant association between SCC grade and CD105 expression among studied cases $(\mathrm{P}=0.001)$ Advanced histological grades of SCC were associated with strong reaction. Poorly differentiated carcinoma was associated with strong stain $(77.7 \%)$ while $(66.6 \%)$ of the weak stain was in well differentiated grade.

TABLE (1) CD105 expression in relation to histological grades among 25 studied OSCC cases

\begin{tabular}{|c|c|c|c|c|c|c|c|}
\hline \multicolumn{2}{|c|}{} & \multirow{2}{*}{$\begin{array}{c}\text { No of } \\
\text { cases }\end{array}$} & \multirow{2}{*}{-ve case } & \multicolumn{3}{|c|}{ CD105 expression } & \multirow{2}{*}{ Total no of +ve cases } \\
\cline { 5 - 8 } & & & weak & mild & strong & \\
\hline $\begin{array}{c}\text { Histological } \\
\text { grade }\end{array}$ & Poorly differentiated & 10 & 1 & 0 & 2 & 7 & $9(90 \%)$ \\
\cline { 2 - 7 } & Well differentiated & 15 & 3 & 8 & 4 & 0 & $12(80 \%)$ \\
\hline \multicolumn{2}{|c|}{} & 25 & 4 & 8 & 6 & 7 & $21(84 \%)$ \\
\hline
\end{tabular}

* statistically significant $(p<0.05)$

TABLE (2) Difference in the mean values of total score of CD 105expression between well and poorly differentiated OSCC.

\begin{tabular}{|c|c|c|c|c|}
\hline \multirow{2}{*}{$\begin{array}{c}\text { Carcinoma } \\
\text { grade }\end{array}$} & \multicolumn{4}{|c|}{$\begin{array}{c}\text { The mean values of total score of CD 105 } \\
\text { immunoexpression }\end{array}$} \\
\cline { 2 - 5 } & $\begin{array}{c}\text { No of } \\
\text { cases }\end{array}$ & $\mathrm{M} \pm \mathrm{Sd}$ & t-value & $\mathrm{p}$-Value \\
\hline $\begin{array}{c}\text { well } \\
\text { differentiated }\end{array}$ & 15 & $3 \pm 1.08$ & 5.62 & $0.0001^{* *}$ \\
\hline $\begin{array}{c}\text { poorly } \\
\text { differentiated }\end{array}$ & 10 & $4.44 \pm 1.16$ & & \\
\hline
\end{tabular}

**High significant difference. $(p<0.001)$.

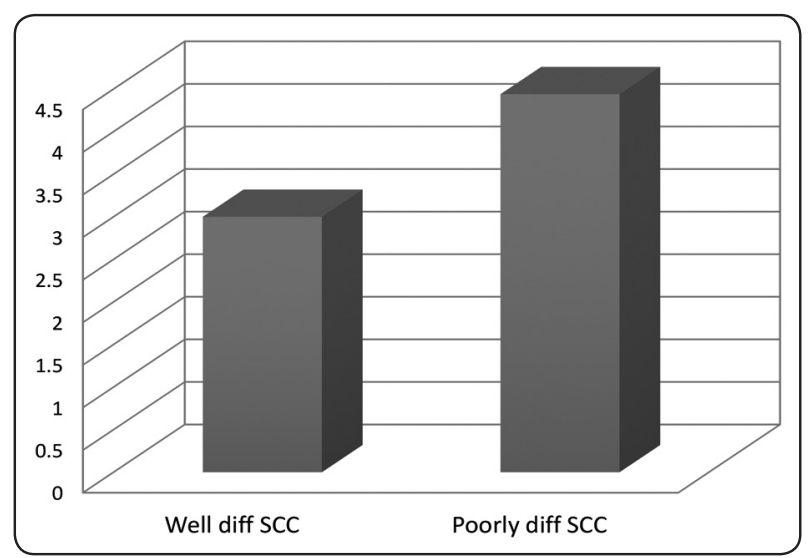

Graph (1): Mean values of MVD in well and poorly differentiated OSCC. 


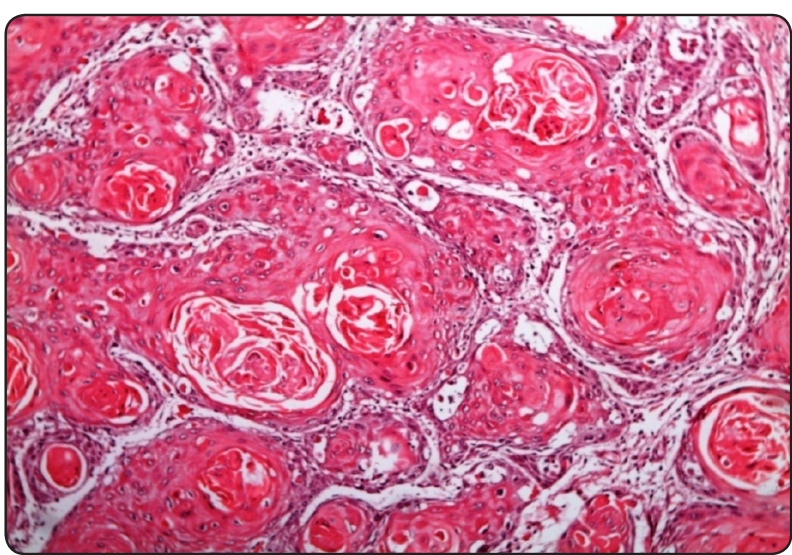

Fig. (1): A photomicrograph of well differentiated OSCC showing numerous keratin pearls (H\&E X100).

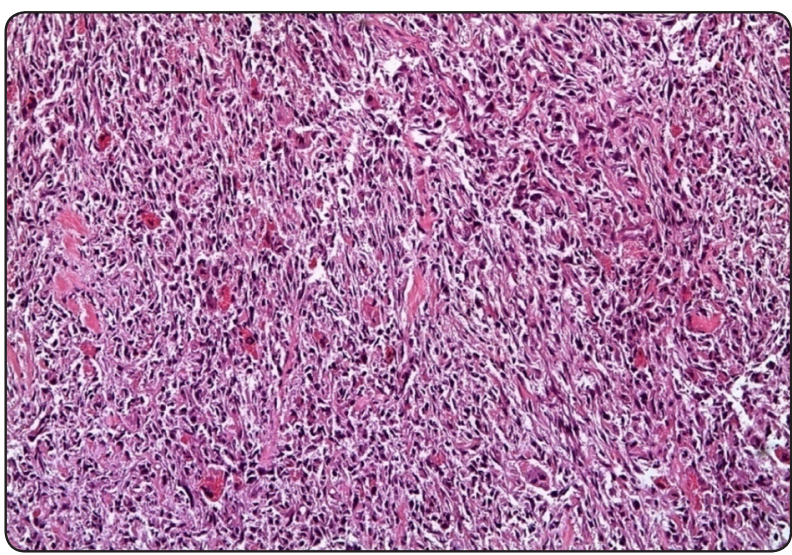

Fig. (2): photomicrograph of poorly differentiated OSCC showing sheets of malignant epithelial cells invading the connective tissue and absence of keratinization (H\&E X100).

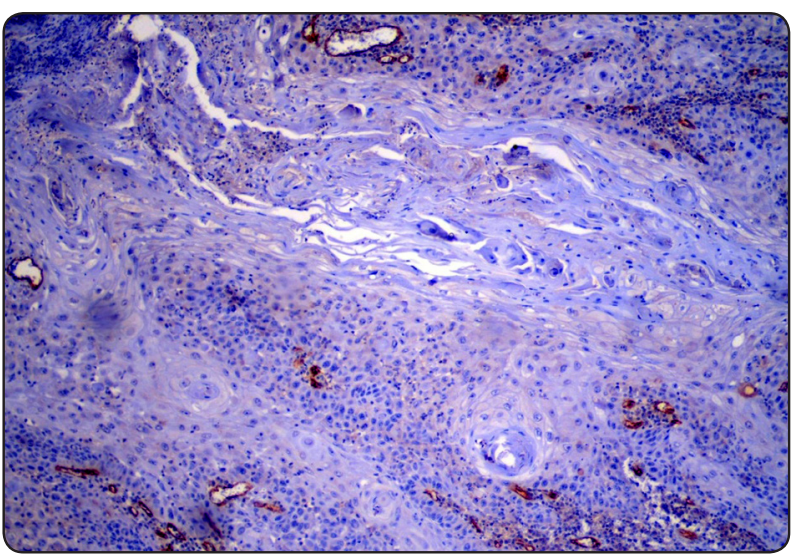

Fig. (3): Photomicrograph showing weak MVD in a case of well differentiated OSCC (DAB X 100).

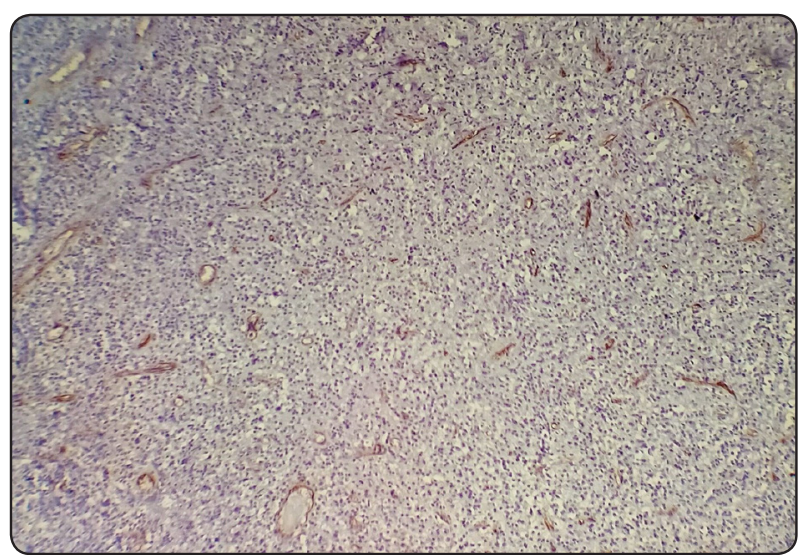

Fig. (4): Photomicrograph of poorly differentiated OSCC showing moderate MVD in endothelial cells (DAB X200).

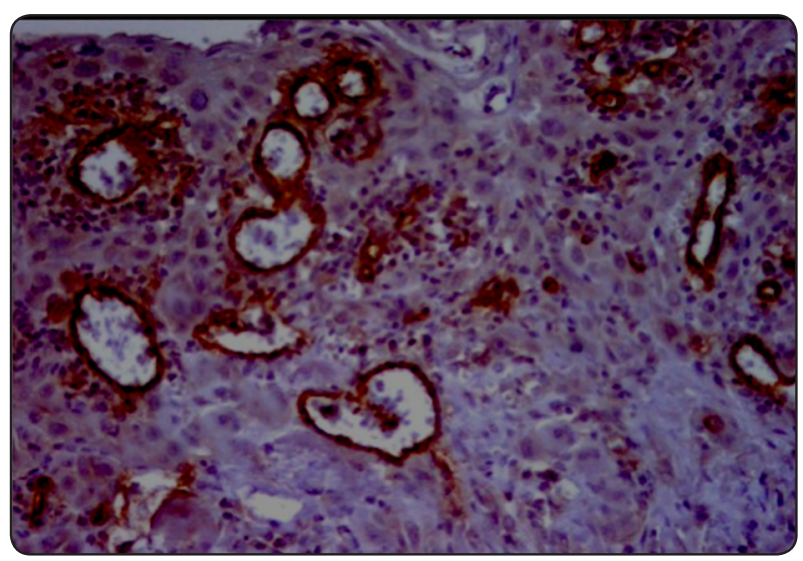

Fig. (5): Photomicrograph of poorly differentiated OSCC showing strong MVD in endothelial cells (DAB X 200).

\section{DISCUSSION}

The angiogenesis phenomenon, which is also known as vascular remodelling, consists of formation of blood vessels from other, pre-existing vessels. Since this phenomenon is a fundamental part of many pathological and physiological processes, including inflammation, repair and tumor growth (Nassiri 2011).

It is generally believed that neo-formed vessels provide nutritional supply to tumor cells and provide favourable conditions for metastatic dissemination. Therefore, the present study was conducted to 
evaluate the quantification of angiogenesis in oral cancer by measuring the MVD, since it is considered as an important prognostic factor which significantly associates with overall survival and correlates with the grades of malignancy (Cardoso et al., 2009). The CD105 (endoglin) seems to reacts specifically with angiogenic endothelial cells and consequently an increasing amount of studies proved a significant association of high MVD with poor prognosis in various neoplasms [Yagasaki et al., 2003].

Several reports had shown that CD105 expression was related to metastasis, whereas there were only few studies investigating CD105 expression in head and neck regions. Several neoplasm have been investigated for Endoglin CD 105 expression including colorectal cancer [Reda et al., 2004], Breast Carcinomas [Jean et al., 2004], clear cell renal cell carcinoma [William Dubinski2012], endometrial carcinoma [Ozlem Erdem et al., 2006], esophageal adenocarcinoma [Reda et al., 2005]; gastric carcinoma [Shigang et al., 2006]; laryngeal squamous cell carcinoma [Elvir Zvrko, et al 2009], advanced Epithelial Ovarian Cancer [Jennifer et al., 2009].

Endoglin expression was studied by many workers in various oral lesions like, oral submucous fibrosis [Raunak et al., 2010], angiogenic squamous dysplasia-like phenomenon in oral epithelial precursor lesions [Siar et al., 2009].

In the present study, an immunohistochemical investigation was done on CD105 expression in oral squamous cell carcinoma. Our aim was to determine the relation of CD105 expression to tumour malignancy grade and its possible role in oral cancer progression.

In this study, we analyzed the differential expression of CD 105 in well and poorly differentiated OSCC, in order to determine the relation of this expression to tumour malignancy grade.

Our results showed that $84 \%$ of OSCC expressed CD 105 with varying immunoreactivity. Previous studies reported 65\%, 96.2\% CD 105 immunopositivity in OSCC (Basnaker et al., 2014, Kyzas., 2006, respectively).

The present results showed that poorly differentiated carcinomas had a significantly higher immunoreactivity of CD 105 than did well differentiated tumours. Consistent to our findings, Schimming \& Marme (2002), also found a relationship between CD 105 expression and high malignancy grade in OSCC

On the other hand, they were not supported by Tadbir et al (2014) who found that there was a decreasing level of CD105 at higher grades of differentiation. In both the intratumoral and invasive front regions, as the clinical stage of the disease progressed, the levels of CD105 expression increased. Likewise, Chien et al, (2006), Khalili et al. (2015) and Miyahara et al (2007), reported the same results. However Mărgăritescu et al. (2010) did not observe any association.

Our results showing a positive association between 105 expression and higher malignancy grading of OSCC. This is based on the fact that CD105 is predominantly active and specifically reacts with proliferating ECs in tissues undergoing angiogenesis. Endothelial cells of vessels secrete important paracrine growth factors for tumor cells such as insulin growth factor-2, basic fibroblast growth factor, and platelet-derived growth factors. By releasing collagenases, urokinases, and plasminogen activators, they facilitate spread of tumor into adjacent fibrin-gel matrix and connective tissue stroma.

In addition to this, Tumor neovascularization promotes growth because the crowded cell population needs these new vessels to allow exchange of nutrients, oxygen and waste products for which the simple diffusion is not adequate. Tumor neovasculature also has structural and functional abnormalities, thus increasing the opportunity of tumor cells to enter the circulation. Altered morphology such as shunt perfusion, absence of vasomotion, blood circulation, and obstruction of microvessels by leukocytes and tumor cells results in functional abnormalities. 


\section{CONCLUSIONS}

The results of our study suggest that CD105 expression is higher in poorly differentiated tumors. CD 105 seems to be a more sensitive and specific marker for microvessel highlights than the usually pan-endothelial markers and have a significant role in the development of OSCC. For these reasons, CD105 may represent a favourable prognostic factor in OSCC and for therapeutic approaches.

\section{REFERENCES}

1. Parkin D. M., Bray F., Ferlay J., Pisani P., Estimating the world cancer burden: Globocan 2000, Int J Cancer, 2001, 94(2):153-156.

2. Farhood, M. Simpson, G.M. Ward, R.J. Walker, N. Osazuwa-PetersDoes anatomic subsite influence oral cavity cancer mortality? A SEER database analysis Laryngoscope, 129 (2019), pp. 1400-1406.

3. Weidner N. (2000): Angiogenesis as a predictor of clinical outcome in cancer patients. Human Pathol; 31(4):403-05.

4. Sebti S., Hamilton A. (2000): Design of growth factor antagonists with antiangiogenic and antitumor properties. Oncogene; 19: 6566-73.

5. Reinmuth N., Parikh A., Ahmad S., Liu W., Stoeltzing O., Fan F., et al. (2003): Biology of angiogenesis in tumors of the gastrointestinal tract. Microsc Res Tech; 60:199-207.

6. Duff S., Jeziorska M., Kumar S., Haboubi N., Sherlock D., O’Dwyer S., et al. (2007): Lymphatic vessel density, microvessel density and lymphangiogenic growth factor expression in colorectal cancer. Colorectal Dis; 9:793-800.

7. Nico B., Benagiano V., Mangieri D., Maruotti N., Vacca A., Ribatti D. (2008): Evaluation of microvascular density in tumors: pro and contra. Histol Histopathol; 23: 601-07

8. Basnaker, Maharudrappa. 2014. "Expression of Endoglin (CD-105) and Microvessel Density in Oral Dysplasia and Squamous Cell Carcinoma." Journal of Clinical and Diagnostic Research 8(9): 91-94.

9. Fonsatti, Ester et al. 2000. "Endoglin Is a Suitable Target for Efficient Imaging of Solid Tumors: In Vivo Evidence in a Canine Mammary Carcinoma Model." Clinical Cancer Research 6(5): 2037-43.

10. Dallas, Nikolaos A. et al. 2008. "Endoglin (CD105): A Marker of Tumor Vasculature and Potential Target for Therapy." Clinical Cancer Research 14(7): 1931-37.
11. Bellon T, Corbi A, Lastres P, Cales C, Cebrian M, Vera S, Cheifetz S, Massague J, Letarte M and Bernabeu C: Identification and expression of two forms of the human transforming growth factor-beta-binding protein endoglin with distinct cytoplasmic regions. Eur J Immunol 23: 2340-2345, 1993.

12. Cheifetz S, Bellon T, Cales C, Vera S, Bernabeu C, Massague $\mathrm{J}$ and Letarte M: Endoglin is a component of the transforming growth factor-beta receptor system in human endothelial cells. J Biol Chem 267: 19027-19030, 1992.

13. Guerrero-Esteo M, Sanchez-Elsner T, Letamendia A and Bernabeu C: Extracellular and cytoplasmic domains of endoglin interact with the transforming growth factor-beta receptors I and II. J Biol Chem 277: 29197-29209, 2002.

14. Fonsatti E, Del Vecchio L, Altomonte M, Sigalotti L, Nicotra MR, Coral S, Natali PG and Maio M: Endoglin: An accessory component of the TGF-beta-binding receptor complex with diagnostic, prognostic, and bioimmunotherapeutic potential in human malignancies. J Cell Physiol 188: 1-7, 2001.

15. Li C, Guo B, Wilson PB, Stewart A, Byrne G, Bundred N and Kumar S: Plasma levels of soluble CD105 correlate with metastasis in patients with breast cancer. Int J Cancer 89: 122- 126, 2000.

16. Zijlmans HJ, Fleuren GJ, Hazelbag S, et al. Expression of endoglin (CD105) in cervical cancer.Br J Cancer.2009;100:1617-1626.

17. Hillen F, Griffioen AW: Tumour vascularization: sprouting angiogenesis and beyond. Cancer Metastasis Rev. 2007, 26(3-4):489-502

18. Liu P, Sun YL, Du J, Hou XS, Meng H. CD105/Ki67 coexpression correlates with tumor progression and poor prognosis in epithelial ovarian cancer.Int J Gynecol Cancer.2012;22:586-92.

19. TadbirA, PardisS, Ashkavandi1 Z. Expression of Ki67 and CD105 as Proliferation and Angiogenesis Markers in Salivary Gland Tumors. 2012.

20. Nassiri F, Cusimano MD, Scheithauer BW, et al. Endoglin (CD105): a review of its role in angiogenesis and tumor diagnosis, progression and therapy. Anticancer Res. 2011;31(6):2283-90.

21. Cardoso S, Souza K, Faria P, et al,. Assessment of angiogenesis by CD105 antigen in epithelial salivary gland neoplasms with diverse metastatic behavior. BMC Cancer $.2009,9: 39$. 
22. Yagasaki H., Kawata N., TakimotoY., Nemoto N: Histopathological analysis of angiogenic factors in renal cell carcinoma, Int J Urol, 2003, 10(4):220-227

23. Reda S Saad, et al. Endoglin (CD105) and vascular endothelial growth factor as prognostic markers in colorectal cancer. Modern Pathology. 2004; 17:197- 203.

24. Jean P, et al. Long-Term Prognostic Significance of Neoangiogenesis in Breast Carcinomas: Comparison of Tie-2/ Tek, CD105, and CD31 Immunocytochemical Expression. Human Pathology. 2004;35(2):176-83.

25. William Dubinski MD. Assessment of the prognostic significance of endoglin (CD105) in clear cell renal cell carcinoma using automated image analysis. Human Pathology. 2012; 43:1037-43.

26. Ozlem Erdem, et al. CD105 expression is an independent predictor of survival in patients with endometrial cancer. Gynecologic Oncology. 2006; 103:1007-11.

27. Reda S, et al. Endoglin (CD105) and vascular endothelial growth factor as prognostic markers in esophageal adenocarcinoma. Human Pathology. 2005; 36:955-61.

28. Shigang Ding MD, et al, Comparative evaluation of microvessel density determined by CD34 or CD105 in benign and malignant gastric lesions. Human Pathology. 2006; 37:861-66.

29. Elvir Zvrko, et al. Prognostic relevance of CD105 assessed microvessel density in laryngeal carcinoma. Otolaryngology-Head and Neck Surgery. 2009; 141:478- 83.

30. Jennifer M. Rubatt, et al, Independent prognostic relevance of microvessel density in advanced epithelial ovarian cancer and associations between CD31, CD105, p53 status, and angiogenic marker expression. A Gynecologic Oncology Group study. Gynecologic Oncology. 2009; 112: 469-74.

31. Raunak Kumar Das, et al, Assessment of malignant potential of oral submucous fibrosis through evaluation of p63,
E-cadherin and CD105 expression. J Clin Pathol. 2010; 63:894-99.

32. Siar $\mathrm{C} \mathrm{H}$, et al, angiogenic squamous dysplasia-like phenomenon in oral epithelial precursor lesions. Eur J Med Res. 2009; 14:315-19

33. Basnaker M, Shashikanth SR, Satish BNVS: Expression of Endoglin (CD-105) and Microvessel Density in Oral Dysplasia and Squamous Cell CarcinomaJ Clin Diagn Res. 2014 Sep; 8(9): ZC91-ZC94.

34. Kyzas P A, Agnantis N J,_Stefanou D: Endoglin (CD105) as a prognostic factor in head and neck squamous cell carcinoma. National Library of Medicine. 2006 Jun; 448(6):768-75.

35. Schimming R, Marme D: Endoglin (CD105) expression in squamous cell carcinoma of the oral cavity. Head and Neack Cancer; 2002 Feb; 24(2):151-6.

36. Tadbir AA, Ashraf MJ, Moradi M. Clinicopathological Significance of CD105 Expression in Squamous Cell Carcinoma of the Oral Cavity. Middle East J Cancer. 2014; 5:7-12.

37. Chien CY, Su CY, Hwang CF, Chuang HC, Hsiao YC, Wu SL, et al. Clinicopathologic significance of CD105 expression in squamous cell carcinoma of the hypopharynx. Head Neck. 2006; 28:441-6.

38. Khalili M, Mahdavi1 N, Beheshti R, Nain F B: Immunohistochemical Evaluation of Angiogenesis and Cell Proliferation in Tongue Squamous Cell Carcinoma. jdt.tums. ac.ir November 2015; Vol. 12, No. 11

39. Miyahara M, Tanuma J, Sugihara K, Semba I. Tumor lymphangiogenesis correlates with lymph node metastasis and clinicopathologic parameters in oral squamous cell carcinoma. Cancer. 2007;110:1287-94.

40. Margaritescu C, Pirici D, Stinga A, Simionescu C, Raica M, Mogoanta L, et al. VEGF expression and angiogenesis in oral squamous cell carcinoma: an immunohistochemical and morphometric study. Clin Exp Med. 2010; 10:209-14 